\title{
Ginger and onion: new and novel considerations
}

\begin{abstract}
Summary
Dyslipidemia is well known factor to increase incidence of heart diseases. This may lead to development of atherosclerotic plaques which is major etiological factor for establishing coronary artery disease (CAD). Hypolipidemic drugs used in allopathy include Statins, Fibric acids, Niacin, and Resins but all have their low compliance due to frequent side effects. Medicinal herbs like Onion and Ginger are hypolipidemic agents commonly used as flavoring agents and making foods spicy and tasty. We have compared hypolipidemic potential between these two medicinal herbs. The study was conducted at Ghurki Trust teaching hospital, Lahore from January to June 2016. Eighty secondary hyperlipidemic patients were enrolled after getting written consent which was approved by Ethics committee of the hospital. They were divided in two equal groups comprising 40 patients in each group. Group-I was treated by Ginger 10 grams daily in three divided doses for 2 months. Group-II was advised to take Onion 200 grams daily in divided amount with each meal i.e.; breakfast, lunch, and dinner for two months. After two months therapy it was observed by statistical analysis that 10 grams ginger reduced TC (total cholesterol) of 38 hyperlipidemic patients $12.4 \mathrm{gm} / \mathrm{dl}$ and LDL-C (low density lipoprotein cholesterol) $27.3 \mathrm{mg} / \mathrm{dl}$. In group-II, onion reduced TC in 35 patients $17.9 \mathrm{mg} / \mathrm{dl}$ and LDL-C $14.8 \mathrm{mg} / \mathrm{dl}$. Changes in tested parameters are significant biostatistically with $p$-values $<0.01$ to $<0.001$. We concluded from this research work that Onion and Ginger reduces risk of CAD by decreasing plasma total cholesterol and LDL cholesterol.
\end{abstract}

Volume 6 Issue I - 2018

\author{
Shah Murad, Khalid Niaz, Azmat Ali, Hina \\ Aslam \\ Department of Pharmacology, Islamabad Medical \& Dental \\ College, Pakistan
}

\author{
Correspondence: Shah Murad, HOD, Department of \\ Pharmacology, Islamabad Medical and Dental College, Main \\ murree road, I 7 Meel, Islamabad, Pakistan, Tel+923 I422434I5, \\ Email shahhmurad65@gmail.com
}

Received: January II, 2018 | Published: February 07, 2018

\section{Introduction}

Metabolic syndrome is not a single disease, rather complication of three diseases i.e., hyperlipidemia, hypertension, and diabetes mellitus. Increased amount of blood lipids cause atherosclerotic phenomenon, which cause hypertension. This process do not stop here, it leads to metabolic alterations of lipids, proteins and carbohydrates naming metabolic syndrome. ${ }^{1-5}$ Metabolic syndrome is complicated to treat by medicines combination therapy including hypoglycemic, hypolipidemic, and hypotensive agents. ${ }^{6}$ Allopathic drug regimens used in metabolic syndrome have low patients compliance due to their lifelong utilization and from mild to severe side effects. ${ }^{7}$ Look at only hypolipidemic allopathic agent's side effects. Statins and Fibrates causes rhambomyolysis (muscular dystrophy) causing muscular pain, Niacin causes flushing resembling to allergic reactions and Resins which are difficult to use for prolonged period due to their metallic taste, and stomach bloating. ${ }^{8}$ Medicinal herbs are alternative therapeutic agents with no or very less frequency, and intensity of side effects. For example onion and ginger are used in various food recipes. These two agents have been proved scientifically as hypolipidemic characteristics. ${ }^{910}$ Onion byproduct contains factors with the ability to modulate plasma lipids and lipoprotein levels. High in vitamin $\mathrm{C}$, onions are a good source of dietary fiber, and folic acid. They also contain calcium, iron, and have a high protein quality. Onions are low in sodium and contain no fat. Onions contain quercetin, a flavonoids; one category of antioxidant compounds. ${ }^{11-13}$ Antioxidants are compounds that help delay or slow the oxidative damage to cells and tissue of the body. ${ }^{14}$ Studies have indicated that quercetin helps to eliminate free radicals in the body, to inhibit low-density lipoprotein oxidation which is an important reaction in the atherosclerosis and coronary heart disease. It also protects and regenerates vitamin $\mathrm{E}$, which is a powerful antioxidant. It also inactivates the harmful effects of chelate metal ions. ${ }^{15-17}$ At least 115 constituents in fresh and dried ginger varieties have been identified by a variety of analytical processes. ${ }^{18}$ Ginger roots contain carbohydrates, sugars, dietary fibers, fat, protein, vitamin $\mathrm{B} 1,2,3,5,6,9$, vitamin $\mathrm{C}$ and vitamin $\mathrm{E}$. It also contains calcium, iron, magnesium, manganese, phosphorous, potassium, sodium, and zinc. ${ }^{19}$ It contains antioxidant compounds like gingerols, shogaol, and paradols. Gingerol inhibits nitric oxide synthesis in activated macrophages and prevents peroxynitrite-induced oxidation and nitration reactions. Peroxynitrite induces DNA base damage predominantly at guanine $(\mathrm{G})$ and 8-oxoguanine (8-oxoG) nucleobases via oxidation reactions..$^{20}$ Generation of free radicals or reactive oxygen species (ROS) during metabolism beyond the antioxidant capacity of a biological system results in oxidative stress, which plays an essential role in heart diseases, neurodegenerative diseases, cancer, and in the aging process. ${ }^{21}$ The bioactive molecules of ginger like gingerols have shown antioxidant activity in various modules. $^{22}$

\section{Material and methods}

This study was conducted at Ghurki Trust Teaching Hospital Lahore, Pakistan from January 2016 to June 2016. Eighty newly diagnosed secondary hyperlipidemic patients were selected with age range from 20 to 60years. Exclusion criteria were peptic ulcer, any gastrointestinal upset, hypothyroidism, diabetes mellitus, renal impairment, and patients suffering from any liver or heart disease. All patients were divided in three equal numerical groups i.e.; 25 in each group. Their baseline vital organ function's data were taken at start of research work i.e.; lipid profile, blood pressure and pulse rate. The study period was sixty days. Forty patients of group-I were advised to take Ginger 10grams daily in divided amount with each meal for two months. Forty patients of group-II were advised to take 200grams Onion daily as salad with breakfast, lunch and dinner for 2 months. Fortnightly follow-up visit was advised to all patients. They were also advised not to take fast or junk food for two months of research study duration. Drug compliance to the regimen was monitored by interview and counseling at each follow-up visits. Serum LDL-cholesterol was calculated by Friedwald formula (LDL- 
Cholesterol=Total Cholesterol-(Triglycerides/5 +HDL-Cholesterol). Data were expressed as the mean \pm SD and " $\mathrm{t}$ " test was applied to determine statistical significance as the difference. A probability value of $<0.01$ was considered as significancant and $\mathrm{P}<0.001$ was considered as highly significant change in the parameter tested in study.

\section{Results}

Results of study are shown in following Table 1. After two months treatment of eighty hyperlipidemic patient's lipid profile's changes before and after treatment were analyzed biostatistically. In group-I two patients discontinued drugs, and in Group-II five patients withdrew from the study due to low compliance of herbs or due to their personal problems. Mean values with \pm SD before and after treatment are shown in following Table 1 with their p-values in Statistical significance column.

Table I Study of newly diagnosed secondary hyperlipidemic patients

\begin{tabular}{llllll}
\hline Group and parameters & At Day-0 & At Day-60 & Overall change & Change in \% & p-value \\
\hline Group-I n=38 & & & & & \\
TC & $269.13 \pm 3.10$ & $256.77 \pm 1.87$ & $12.4 \mathrm{mg} / \mathrm{dl}$ & 4.6 & $\mathrm{P}<0.01$ \\
LDL-C & $177.64 \pm 2.02$ & $150.32 \pm 1.98$ & $27.3 \mathrm{mg} / \mathrm{dl}$ & 15.4 & $\mathrm{p}<0.001$ \\
Group-II $\mathbf{n = 3 5}$ & & & & & \\
TC & $287.33 \pm 2.00$ & $269.44 \pm 3.01$ & $17.9 \mathrm{mg} / \mathrm{dl}$ & 6.2 & $\mathrm{p}<0.01$ \\
LDL-C & $203.17 \pm 2.22$ & $188.42 \pm 1.85$ & $14.8 \mathrm{mg} / \mathrm{dl}$ & 7.3 & $\mathrm{P}<0.01$ \\
\hline
\end{tabular}

TC=group-I=ginger; Group-II=Onion; Total cholesterol, LDL-C=low density lipoprotein cholesterol; $n=$ sample size; \pm indicates SEM, P-values <0.0I=significant change in the parameter; P-value $<0.00 \mathrm{I}=$ highly significant changes in the tested parameters

\section{Discussion}

Cardiovascular problems in human population are mainly related with acquired facts like sedentary life style, smoking, alcohol use, utilization of drugs without prescription, and high intake of junk foods..$^{23}$ Elevated oxidant stress linked to pro-inflammatory conditions contributes to the development of alterations in the bioavailability of vascular nitric oxide and some endothelial cell dysfunctions that can culminate in profound impairments to vascular reactivity. ${ }^{24}$ Low density lipoproteins in plasma will be oxidized, if there is burden of reactive oxygen species (ROS) in human body. ${ }^{25}$ Atherosclerotic plaques leading to cause coronary artery disease is key factor for morbidity/mortality all over the world. To reduce hyperlipidemic state is essential step to decrease risk of CAD. ${ }^{26}$ Allopathic hypolipidemic medicines are being replaced by herbal hypolipidemic agents due to wide range of pharmacological actions produced by allopathic drug regimens. ${ }^{27}$ Ginger have had been used since long to treat gastrointestinal, respirac toy, skin, pulmonary, brain, heart diseases. Ginger root contains a very high level $(3.85 \mathrm{mmol} / 100 \mathrm{~g})$ of total antioxidants, surpassed only by pomegranate and some types of berries. ${ }^{28}$ Ginger was reported to suppress TPA-induced oxidative stress in human promyelocytic leukemia. ${ }^{29}$ In some research works it have been proved that ginger compounds effectively inhibit superoxide production. ${ }^{30}$ Several reports indicate that ginger suppresses lipid peroxidation and protects the levels of reduced glutathione. ${ }^{31}$ Ginger was reported to decrease age-related oxidative stress markers and was suggested to guard against ethanol-induced hepatotoxicity by suppressing oxidative consequences in rats treated with ethanol. ${ }^{32}$ When we used 10grams of ginger root in 38 hyperlipidemic patients, it reduced total cholesterol in plasma $12.4 \mathrm{mg} / \mathrm{dl}$ and LDL cholesterol reduction was $27.3 \mathrm{mg} / \mathrm{dl}$ in two months. Same results were observed in study conducted by Makroue S et al., ${ }^{33}$ who used ginger roots 12 grams daily in 49 hyperlipidemic patients for three months. Palisa V et al. ${ }^{34}$ explained mechanism of action of ginger as antioxidant that it scanege free radicles in plasma due to its content i.e.; gingerol. Palisa V et al. ${ }^{34}$ proved $13 \%$ decrease in TC, and $17 \%$ decrease in LDL cholesterol when they used 8 grams of ginger roots in 103 hyperlipidemic patients for six months. This mismatch in two studies may be due to large sample size and ingestion of drug used for long period. Recently, great attention has been focused on the role of the antioxidative defense system in oxidative stress. Endogeneous antioxidants in medicinal herbs may play an important role in antioxidative defense against oxidative damage, possibly protecting the biological functions of cells. There is increasing interest in the protective biological function of natural antioxidants contained. ${ }^{35}$ Onion when we used in 35 hyperlipidemic patients it reduced plasma total cholesterol $17.9 \mathrm{mg} / \mathrm{dl}$, and LDL cholesterol $14.8 \mathrm{mg} / \mathrm{dl}$ in two months therapy. These results match with research study conducted by Mustavye J et al. ${ }^{36}$ who proved almost same changes in these two parameters of lipid profile in 55 hyperlipidemic patients when they used 100 grams of onion for two weeks only. These results are in contrast with our results. May be the environmental factors change research study results. We restricted junk food to our patients and keep continue brisk walk for half an hour daily for the duration of study period. The antioxidant action of ginger has been proposed as one of the major possible mechanisms for the protective actions of the plant against a number of toxic agents such as carbon tetrachloride and cisplatin. Recently, it has been shown that 6-gingerol is endowed with strong anti-oxidant action both in vivo and in vitro, in addition to strong anti-inflammatory and anti-apoptotic actions. ${ }^{37}$ Floreie $\mathrm{C}$ et al. ${ }^{38}$ mentioned that numerous enzymatic and nonenzymatic mechanisms take place to protect the cell against oxidative damage. The radical chain reaction of lipid peroxidation appears to be a continuous physiological process. This process, if out of control, can alter essential cell functions and lead to cell death. ${ }^{39}$ Reactive oxygen species (ROS) can be detoxified by an enzyme defense system, comprising superoxide dismutase (SOD), catalase (CAT), and selenium-dependent glutathione peroxidase, or non-enzymatic systems by the scavenging action of GSH, while organic peroxides can be detoxified by the activity of glutathione S-transferase (GST). ${ }^{40}$ Onion contains phytochemicals that can increase detoxifying enzymes for ROS, but exact mechanism is not known yet. ${ }^{41}$ A group of volunteers fed a high fat diet plus $100 \mathrm{~g}$ onion once a day and those fed fat diet only showed a significant decrease in 
serum triglycerides, but not cholesterol, as compared to those only fed with fat diet only. Another study reported that oral administration of a butanol onion extract to patients with elementary lipemia prevented an increase in total serum cholesterol, Jlipoprotein cholesterol, and J-lipoprotein and serum triglycerides. Gyvesta YF et al. ${ }^{42}$ described that quercetin (one of the content of onion) has been shown to have antioxidant activity related to a strong scavenging capacity. Various studies have had proved fundamental use of phyto chemical to reduce risk for coronary artery diseases as mentioned by Noor $\mathrm{M}$ et al ${ }^{43} \mathrm{Jan}$ MM et al., ${ }^{44}$ proved same effects of onion extracts used in rats and found this phyto chemical quercetin (present in onion) as potent as statins as hypolipidemic agent. Fovuca $\mathrm{M}$ et al. ${ }^{45}$ explained that onion is natural antioxidant plant and it works as modulator of detoxification in human population.

\section{Conclusion}

It was concluded from this work that medicinal plants can be used with good compliance to reduce high plasma lipids leading to reduce incidence of coronary artery diseases (CAD).

\section{Acknowledgements}

None.

\section{Conflict of interest}

Author declares that there is no conflict of interest.

\section{References}

1. Saliha B, Sipahib T, Donmez EO. Ancient nigella seeds from Boyali Hoyuk in north-central Turkey. J Ethnopharmacol. 2011;124(3):416-420.

2. Bruckert E, Labreuche J, Amarenco P. Meta-analysis of the effect of nicotinic acid alone or in combination on cardiovascular events and atherosclerosis. Atherosclerosis. 2010;210(2):353-361.

3. Boekholdt SM, Sandhu MS, Day NE, et al. Physical activity, C-reactive protein levels and the risk of future coronary artery disease in apparently healthy men and women: the EPIC-Norfolk prospective population study. Eur J Cardiovasc Prev Rehabil. 2006;13(6):970-976.

4. Kawaguchi K, Mizuno T, Aida K, et al. Hesperidin as an inhibitor of lipases from porcine pancreas and Pseudomonas. Biosci Biotechnol Biochem. 1997;61(1):102-104

5. Panchal SK, Poudyal H, Iyer A, et al. High-carbohydrate, high-fat diet-induced metabolic syndrome and cardiovascular remodeling in rats. $J$ Cardiovasc Pharmacol. 2011;57(5):611-624.

6. Jia G, Aroor AR, Whaley Connell AT, et al. Fructose and uric acid: Is there a role in endothelial function? Curr Hypertens Rep. 2014;16(6):434

7. Goto T, Teraminami A, Lee JY, et al. Tiliroside, a glycosidic flavonoid, ameliorates obesity-induced metabolic disorders via activation of adiponectin signaling followed by enhancement of fatty acid oxidation in liver and skeletal muscle in obese-diabetic mice. $J$ Nutr Biochem. 2012;23(7):768-776.

8. Mittal MK, Florin T, Perrone J, et al. Toxicity from the use of niacin to beat urine drug screening. Ann Emerg Med. 2007;50(5):587-590.

9. Faure P, Rossini E, Wiernsperger N, et al. An insulin sensitizer improves the free radical defense system potential and insulin sensitivity in high fructose-fed rats. Diabetes. 1999;48(2):353-357.

10. Assayed ME. Radioprotective effects of black seed (Nigella sativa) oil against hemopoietic damage and immunosuppression in gamma-irradiated rats. Immunopharmacol Immunotoxicol. 2010;32(2):284-296.
11. Xu J, Racke MK, Drew PD. Peroxisome proliferator-activated receptor-alpha agonist fenofibrate regulates IL-12 family cytokine expression in the CNS: relevance to multiple sclerosis. J Neurochem. 2007;103(5):1801-1810.

12. Capuzzi DM, Morgan JM, Brusco OA, et al. Niacin dosing: relationship to benefits and adverse effects. Curr Atheroscler Rep. 2000;2(1):64-71.

13. Birgit Gustafson. Adipose Tissue, Inflammation and Atherosclerosis. Journal of Atherosclerosis and Thrombosis. 2010;17(4):332-341.

14. Tappy L, Le KA, Tran C, et al. Fructose and metabolic diseases: new findings, new questions. Nutrition. 2010;26(11-12):1044-1049.

15. Halliwell B, Rafter J, Jenner A. Health promotion by flavonoids, tocopherols, tocotrienols, and other phenols: direct or indirect effects? Antioxidant or not?. Am J Clin Nutr. 2005;81(Suppl 1):S268-S276.

16. Khitan Z, Kim DH. Fructose: a key factor in the development of metabolic syndrome and hypertension. J Nutr Metab. 2013;2013:682673.

17. Gonzalez Pena D, Angulo J, Vallejo S, et al. High-cholesterol diet enriched with onion affects endothelium-dependent relaxation and NADPH oxidase activity in mesenteric microvessels from Wistar rats. Nutr Metab. 2014; $11: 57$.

18. Kostapanos MS, Liamis GL, Milionis HJ, et al. Do statins beneficially or adversely affect glucose homeostasis? Curr Vasc Pharmacol. 2010;8(5):612-631.

19. Sarwar N, Danesh J, Eiriksdottir G, et al. Triglycerides and the risk of coronary heart disease: 10,158 incident cases among 262,525 participants in 29 Western prospective studies. Circulation. 2007;115(4):450-458.

20. Bjerregaard LJ, Joensen AM, Dethlefsen C, et al. Fish intake and acute coronary syndrome. Eur Heart J. 2010;31(1):29-34.

21. Balk EM, Tatsioni A, Lichtenstein AH, et al. Effect of chromium supplementation on glucose metabolism and lipids: a systematic review of randomized controlled trials. Diabetes Care. 2007;30(8):2154-2163.

22. Bertelli AA, Das DK. Grapes, wines, resveratrol, and heart health. J Cardiovasc Pharmacol. 2009;54(6):468-476.

23. Ahn J, Ambrosone CB, Kanetsky PA, et al. Polymorphisms in genes related to oxidative stress (CAT, MnSOD, MPO, and eNOS) and acute toxicities from radiation therapy following lumpectomy for breast cancer. Clin Cancer Res. 2006;12(23):7063-7070.

24. Akimoto AK, Miranda Vilela AL, Alves PCZ, et al. Evaluation of gene polymorphisms in exercise-induced oxidative stress and damage. Free Radic Res. 2010;44(3):322-331.

25. Akyol O, Yanik M, Elyas H, et al. Association between Ala-9Val polymorphism of Mn-SOD gene and schizophrenia. Prog Neuropsychopharmacol Biol Psychiatry. 2005;29(1):123-131.

26. Alves Silva J, Santos MS, Ferreira ACS, et al. The ancestry of Brazilian mtDNA lineages. Am J Hum Genet. 2000;67(2):444-461.

27. Ambrosone CB, Freudenheim JL, Thompson PA, et al. Manganese superoxide dismutase (MnSOD) genetic polymorphisms, dietary antioxidants, and risk of breast cancer. Cancer Res. 1999;59(3):602-606.

28. Barreiro LB, Laval G, Quach H, et al. Natural selection has driven population differentiation in modern humans. Nat Genet. 2008;40(3):340-345.

29. Bastaki M, Huen K, Manzanillo P, et al. Genotype-activity relationship for Mn-superoxide dismutase, glutathione peroxidase 1 and catalase in humans. Pharmacogenet Genomics. 2006;16(4):279-286.

30. Bica CG, Cruz IBM, Silva LLM, et al. Association of manganese superoxide dismutase gene polymorphism (Ala-9Val) and breast cancer in males and females. J Bras Patol Med Lab. 2007;43(3):219-225. 
31. Brigelius Flohe R. Tissue-specific functions of individual glutathione peroxidases. Free Radic Biol Med. 1999;27(9-10):951-965.

32. Excoffier L, Laval G, Schneider S. Arlequin (version 3.0): an integrated software package for population genetics data analysis. Evol Bioinform Online. 2007;1:47-50.

33. Makroue S, Apazian RS, Omaloi R, et al. Natural chemical compounds and herbs for heart diseases. J Nut Plant. 2016;12(2):1666-1667.

34. Benn M, Watts GF, Tybjaerg Hansen A, et al. Familial hypercholesterolemia in the Danish general population: prevalence, coronary artery disease, and cholesterol-lowering medication. J Clin Endocrinol Metab. 2012;97(11):3956-3964.

35. Parlakpinar H, Olmez E, Acet A, et al. Beneficial effects of apricot-feeding on myocardial ischemia-reperfusion injury in rats. Food Chem Toxicol. 2009;47(4):802-808.

36. Brayton J, Qing Z, Hart MN, et al. Influence of adhesion molecule expression by human brain microvessel endothelium on cancer cell adhesion. J Neuroimmunol. 1998;89(1-2):104-112.

37. Connor WE, Connor SL. Importance of diet in the treatment of familial hypercholesterolemia. Am J Cardiol. 2012;72(10):42-53.

38. Olszewska M, Glowacki R, Wolbis M, et al. Quantitative determination of flavonoids in the flowers and leaves of Prunus spinosa L. Acta Pol Pharm. 2001;58(3):199-203.
39. Chen SJ, Rader DJ, Tazelaar J, et al. Prolonged correction of hyperlipidemia in mice with familial hypercholesterolemia using an adeno-associated viral vector expressing very-low-density lipoprotein receptor. $\mathrm{Mol}$ Ther. 2000;2(3):256-261.

40. Cho E, Seddon JM, Rosner B, et al. Prospective study of intake of fruits, vegetables, vitamins, and carotenoids and risk of age-related maculopathy. Arch Ophthalmol. 2009;122(6):883-892.

41. Schectman G, Hiatt J. Drug therapy for hypercholesterolemia in patients with cardiovascular disease: factors limiting achievement of lipid goals. Am J Med. 2013;100(2):197-204.

42. Furberg CD, Pitt B. Withdrawal of cerivastatin from the world market. Curr Control Trials Cardiovasc Med. 2001;2(5):205-207.

43. Shah M, Shah S, Khandekar R. Ocular injuries and visual status before and after their management in the tribal areas of Western India: a historical cohort study. Graefes Arch Clin Exp Ophthalmol. 2008;246(2):191-197.

44. Jan MM, Fohsin JJ, Lukver TT, et al. Onion is best plant to treat hyperlipidemia in albino rats. EJM. 2013;2(4):1123-1128.

45. Fovuca M, Sulmin S, Kovachi F, et al. Hypolipidemic effects of various plants. EJ Cl Cardiol. 2013;7(7):435-439. 